\title{
Assessing the Distribution of Household Financial Contribution to Health System: A Case Study of Iran
}

\author{
Amir Abbas Fazaeli ${ }^{1,2}$, Mohmmad Hadian ${ }^{1}$, Aziz Rezapour ${ }^{1,3}$ \& Ali Akbar Fazaeli ${ }^{4,5}$ \\ ${ }^{1}$ Departments of Health Economics, School of Health Management and Information Sciences, Iran University of \\ Medical Sciences, Tehran, IR Iran \\ ${ }^{2}$ Iranian Social Security Organization, Tehran, IR Iran \\ ${ }^{3}$ Health Management and Economics Research Center, Iran University of Medical Sciences, Tehran, IR Iran \\ ${ }^{4}$ Research Social Determinants of Health Research Center \& Department Health Management, School of Public \\ Health, Hamedan University of Medical Sciences, Hamedan, IR Iran \\ ${ }^{5}$ Research Center for Health Sciences \& Department Health Management, School of Public Health, Hamedan \\ University of Medical Sciences, Hamedan, IR Iran \\ Correspondence: Mohmmad Hadian, School of Health Management and Information Sciences, Iran University \\ of Medical Sciences, No 6, Rashid Yasemi st., Vali-e-asr Ave., Tehran 1995614111, IR Iran. Tel: \\ 98-21-8888-3334. E-mail: hadianmohamad@yahoo.com
}

\author{
Received: December 24, 2015 Accepted: January 19, 2016 Online Published: February 24, 2016 \\ doi:10.5539/gjhs.v8n10p233 URL: http://dx.doi.org/10.5539/gjhs.v8n10p233
}

\begin{abstract}
Background: Throughout the world, financing the healthcare system through households' financial contribution is a challenging issue in evaluating performance of healthcare systems. The purpose of this paper is illustrating the consequences of Iranian household to health system financial contribution in terms of burden and incomes approaches.
\end{abstract}

Method: The Data derived from an annual survey by Statistics Center of Iran (SCI) on expenditure-income of 36,551 households in 2012 was used to analyze countrywide distribution indicators of households' medical expenses by measuring indices of Income and burden approaches based on World Health Organization (WHO) and World Bank recommended methodologies.

Results: The fairness in financial contribution index was 0.85 and 0.82 , and the income redistributive effect index was 0.54 and 0.3 in urban and rural areas, respectively. The fairness in financial contribution index was found 0.84 and 0.83 and the income redistributive effect index was 0.48 and 0.25 for households with and without medical insurance, respectively.

The percentages of household with catastrophic health payments were $2.4 \%$ and $4 \%$ and the change in the number of household falling below the poverty line due to health system payments was $0.4 \%$ and $2 \%$ in urban and rural areas, respectively. The percentages of household with catastrophic health payments were $2.8 \%$ and $3 \%$ and the change in the number of household falling below the poverty line due to health system payments was 0.008 and 0.011 for households with and without medical insurance, respectively.

Conclusion: Distribution indicators of medical expenses were more favorable in urban areas compared to rural areas and Medical insurance has declined impoverishment risks and number of people suffered due to catastrophic health expenditure.

In addition, the result showed that there are different approaches for analyzing the distribution of out of pocket payments which used to complement each other in respect of formulation and development policy making in health system.

Keywords: redistributive effect, faire financial contribution index, catastrophic health expenditures

\section{Introduction}

Over the two recent decades, Analyzing and understanding the distribution household financial contribution to health system has been one of the important aspects of any health system performance assessment (Murray et al., 
2000; Murray et al., 2006; Kutzin, 2013).

The World Health Report 2000 (World Health Organization, 2000) contributed to this heightened attention towards health system financing arrangements (McIntyre, 2010) by emphasizing that, effective financing of a healthcare system should aim to provide sufficient resources for people's access to public and individual health services, in order to protect them against impoverishment due to household health expenditure.

In general, the analysis of the consequences of household health system contributions can be divided into two broad approaches: the income approach and the burden approach. The former examines the effect of health system payments in the space of income. The key concern is the marginal effect of health systems financing arrangements on the broader construct of total household income. The effects in the space of income have been measured in terms of changes in its distribution and changes in levels of poverty (O'Donnell et al., 2008). The latter examines health system payments in terms of the impact or disutility experienced by households because of these payments (Murray et al., 2003).

To further clarify the conceptual distinction between the income and the burden approaches, Table 1 summarizes the main approaches and types of measurements that are possible.

Table 1. Main indicators used in the income and burden approaches to analyzing the consequences of household health system payments

\begin{tabular}{lll}
\hline Approach & Complete distribution & Threshold \\
\hline \multirow{2}{*}{ Income } & $\begin{array}{l}\text { Change in the distribution of income due to } \\
\text { health system payments (redistributive } \\
\text { effect or RE) }\end{array}$ & $\begin{array}{l}\text { Change in the number of households falling below the } \\
\text { poverty line due to health system payments (DH) }\end{array}$ \\
$\begin{array}{l}\text { Distribution of disutility or burden due to } \\
\text { health system payments (fairness } \\
\text { financial contribution index or FFC) }\end{array}$ & $\begin{array}{l}\text { Households above a threshold level of disutility or } \\
\text { burden due to health system payments (Percentage of } \\
\text { households with catastrophic payments or CAT\%) }\end{array}$ \\
\hline
\end{tabular}

In Iran, Protecting households against excessive and catastrophic health out of pocket (OOP) has a prominent role in national policy making (Larijani et al., 2009).

Accordingly, the article 29 of the Constitution of Islamic Republic of Iran states that all people have the right to enjoy health and medical services under social security cover, public resources and insurance, and the government is obliged to provide these services. The issue is of such importance that paragraph 12 of article 3 of the Constitution addresses provision of welfare and elimination of poverty with emphasis on health and insurance as proper and equitable foundation of economy based on Islamic principles (Moghaddam et al., 2013).

In this regard, indicators of healthcare system financing were proposed as strategic goals in the five-year development plans (5YDP), and quantitative goals were set forth. The article 90 in 4th 5YDP (2005-2010) said that: "In order to increase equitable access to health services and reducing the shares of vulnerable and low income families in health expenditures, distributional policies of the health resources and facilities should be modified by the state in a way to achieve the following strategic goals: increasing the fair financial contribution index to 0.90 ; reducing share of out of pocket to maximum $30 \%$ and reducing the percentage of household facing Catastrophic health expenditure to 1\% (Economic, 2004). Accordingly, the article 38 of $5^{\text {th }} 5$ YDP (2011-2015) Act considers the health insurance by emphasizing on "Quantitative and qualitative improvement of health insurance" (Moghaddam et al., 2013).

During the past decade, in following of new policymaking approach to the issue of financing the health system, there has been considerable interest in analyzing the distribution of household health expenditure in Iran that upon the income and burden approaches can be categorized only based on the income approach (Zare et al., 2014; Hajizadeh \& Connelly, 2015; Ghiasvand et al., 2015) or the burden approach (Razavi, Hassanzadeh, \& Basmenji, 2005; Mehrara \& Fazaeli, 2010; Fazaeli et al., 2015).

Therefore, according to mentioned issues, the main contribution of this paper is applying household survey data to illustrate the two different approaches to analyzing the consequences of household health system contributions, simultaneously. This empirical assessment helps to clarify the difference between distribution of insured and noninsured household to financial contribution health system in urban and rural area and provides appropriate evidence for health financing policy making. 


\section{Materials and Methods}

\subsection{Database}

The national database of Statistical Centre of Iran (SCI) on urban and rural household's income and expenditure survey (HIES) which is conducted annually was used. In the survey a questionnaire with four sections including demographic, kind of residency and the equipment, consumable and non-consumable costs, and household income is used. The costs related to health issues include four subgroups: drug and medical equipment; out patient's services; in-patients services and detoxification and rehabilitation. (Fazaeli et al., 2015)

\subsection{Sampling}

Population includes all private and collective settled households in urban and rural areas. A three-staged cluster sampling method with strata is used in the Survey, at the first stage the census areas are classified and selected. At the second stage, the urban and rural blocks are selected and the selection of sample 'households is done at the third stage. In order To obtain estimations more representative of the whole year, the samples are evenly distributed between the months of the year. The number of sample that is carried out in this study was 16937 urban and 19614 rural household. The weighted numbers of households were 15275217 and 5613772 in urban and rural, respectively.

\subsection{Indices Calculation}

Main indicators used in the income and burden approaches to analyzing the consequences of household health system payments are calculated by data extracted from HIES:

- Fair Financial Contribution Index (FFCI) and catastrophic health expenditure (CATHE):

FFCI is an indicator for the financial equity. It was constructed to vary from 0 to 1 ; the fairer the health financing system, the closer FFC will be to 1 . Was calculated by the following formula (Xu, 2005):

$$
F F C I=1-\sqrt[3]{\frac{\sum_{h=1}^{n} w_{h} / \operatorname{oopct}_{h}-\operatorname{oopctp}_{0} / 3}{\sum w_{h}}}
$$

Where, $\left(\mathrm{OOPCTP}_{\mathrm{h}}\right)$ defined as the household's total cash paid directly for the health care services $\left(\mathrm{OOP}_{\mathrm{h}}\right)$ dividing by the capacity to pay $\left(\mathrm{CTP}_{\mathrm{h}}\right)$ and oopctp $p_{0}=\sum w_{h} O o p_{h} / \sum w_{h} c t p_{h}$.

In the context of $\operatorname{OOPCTP}_{\mathrm{h}}$, as this indicator is increased, the household are forced to reduce other living costs in order to save the money for buying health care services. In such condition, many families decrease their payments to recreational activities which subsequently reduce their welfare and quality of life. There is a critical cut off for this reduction. The catastrophic health expenditure (CATHE) has been set as $40 \%$ or more of the household capacity to pay

\section{- Poverty Headcount Difference (DH):}

Denoting the percentage of households under the poverty line after health payments as Ha and before health payments as $\mathrm{Hb}$, the headcount difference DH is given as (Murray et al., 2003):

$\mathrm{DH}=\mathrm{Ha}-\mathrm{Hb}$

\section{- Gini coefficient (GC) and Concentration Index(CI):}

The Gini coefficient is one of the most popular measures of inequality. One of its many formulations is based on a covariance expression:

$$
\operatorname{GINI}(X)=-2 \operatorname{Cov}\left(\frac{x}{\mu(x)},(1-F(x))\right)
$$

Where $X$ is a random variable of interest with mean $\mu(X)$, and $F(X)$ is its cumulative distribution function. Closely related to the Gini coefficient is the Concentration index (CI). The CI measures the association between two random variables and can be expressed as 


$$
\operatorname{CoNC}(X, Y)=-2-2 \operatorname{Cov}\left(\frac{x}{\mu(x)},(1-G(x))\right)
$$

Where $\mathrm{G}(\mathrm{Y})$ is the cumulative distribution function of $\mathrm{Y}$. $\mathrm{CONC}(\mathrm{X}, \mathrm{Y})$ reflects how much $\mathrm{X}$ is concentrated on observations with high ranks in Y (Van Kerm, 2009).

\section{- Kakwani index:}

The index is calculated as $\pi_{\mathrm{k}}=\mathrm{CI}-\mathrm{GC}$, where $\mathrm{CI}$ is the concentration index for the Household health payment and GC is the Gini coefficient of the living standards measure (Income). The value of $\pi_{\mathrm{k}}$ ranges from -2 to 1 . A negative number indicates regressivity. A positive number indicates Progressivity. In the case of proportionality, the concentration lies on top of the Lorenz curve and the index is zero (O'Donnell, 2008).

\section{- The redistributive effect (RE):}

Unlike the Kakwani index which measures departures from proportionality, the Reynolds-Smolensky index (Reynolds \& Smolensky, 2013), often called the redistributive effect (RE), measures the extent to which the tax system redistributes income. Denoting the after-payment Gini coefficient by Gx-t, the redistributive effect is:

$$
R E=G_{X}-G_{X-t}
$$

The index is defined in the range [-1,1], a negative value indicating regressivity and redistribution towards the better-off, and positive values pointing to the opposite (Murray et al., 2003).

\section{Results}

About $73.5 \%$ of the national population is covered by social security medical insurance, with urban and rural proportions $67.8 \%$ and $89.1 \%$, respectively. As a proportion of the whole population, the coverage in urban has increased from $29 \%$ in the first decile to $83 \%$ in the tenth, and rural areas from $87 \%$ in the first decile to $92 \%$ in the highest income decile.

The ability to pay is 1.3 times greater among the insured compared to the uninsured, and 1.8 times greater in urban households compared to rural ones.

On average, $7.4 \%$ of households' payment capacity is spent on medical services. This indicator is $6.8 \%$ and $9 \%$ in urban and rural areas respectively, and $7.6 \%$ and $7 \%$ among the insured and the uninsured.

On average $68.7 \%$ of people have used at least one medical service, with the insured 8 units more than the uninsured $(71 \% \mathrm{~V} 63 \%)$. Use of all medical services (except for outpatient services in clinics) is also more by the insured than by the uninsured, with the greatest difference in diagnostic services with 1.4 times followed by inpatient services with 1.3 times. Interestingly, the insured have used outpatient services (such as kidney-stone/ESWL, outpatient surgeries, chemotherapy ....) less than the uninsured.

Medical services are equally used by urban and rural people (about $68.7 \%$ ); they also equally use inpatient services (about 12.6\%). However, rural people visit outpatient clinics 1.4 times more than urban people, and in contrast, Para clinics and dentists are visited by urban people 1.2 times more than by rural people.

Payment of health expenditure reduces Gini coefficient (income inequity) among households. Gini coefficient is higher in urban areas than in rural ones. Yet, insurance cover has had different effects on income redistribution of health expenditure in urban and rural areas (Figure 1). After payment of medical costs, the difference in Gini coefficient between uninsured and insured households increased from 0.01 to 0.013 , suggesting that insurance can increase household income distribution equity after payment of medical costs. 


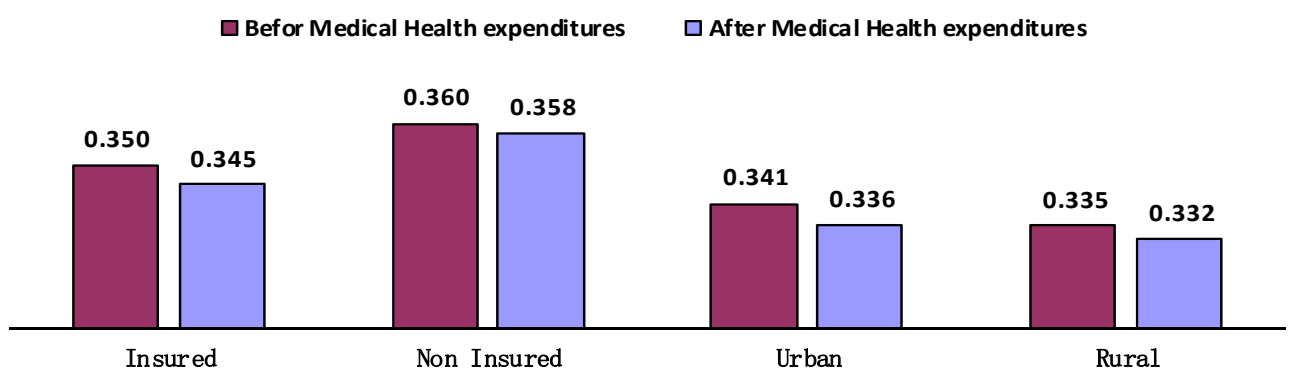

Figure 1. The Gini coefficient in Iran, 2012

For the sample studied, RE index is 0.0043 , indicating progressivity of financial contributions to health system in Iran. This indicator is 1.8 times higher in urban areas compared to rural ones, and 1.9 times higher among the insured compared to the uninsured. In contrast to urban areas, insurance cover in rural areas has reduced the effect of medical costs on income distribution. In urban areas, the effect of redistribution of medical costs is 2.3 times higher among the insured compared to the uninsured, and in rural areas, this effect is 0.64 times higher.

Table 2. The redistributive effects (RE) in Iran, 2012

\begin{tabular}{llll}
\hline RE & INSURED & UNISURED & TOTAL \\
\hline URBAN & 0.006334 & 0.002726 & 0.0054 \\
RURAL & 0.002931 & 0.004565 & 0.0030 \\
TOTAL & 0.004768 & 0.002479 & 0.0043 \\
\hline
\end{tabular}

Assessment Change in the number of households falling below the poverty line due to health system payments (DH), in which threshold relates to income distribution approach showed that at national level about $0.9 \%$ of people are impoverished by medical costs (Table 3). The DH index in rural areas is 5.5 times higher compared to urban areas. Insurance cover has led to a significant reduction in medical costs impoverishment index in urban areas compared to rural areas, such that insured to uninsured DH in urban and rural areas are 8.5 times and 1.1 times, respectively. Interestingly, DH among the rural insured people is 21.6 times the urban insured.

Table 3. Poverty headcount difference (DH) in Iran, 2012

\begin{tabular}{llll}
\hline DH & INSURED & UNISURED & TOTAL \\
\hline URBAN & 0.000975 & 0.008272 & 0.0038 \\
RURAL & 0.021105 & 0.02264 & 0.0209 \\
TOTAL & 0.008032 & 0.011048 & 0.0088 \\
\hline
\end{tabular}

Fair financial contribution index (FFCI) is 0.873 at national level, and significantly better in urban compared to rural areas (Table 4). Medical costs are more fairly distributed among the insured compared to uninsured in both urban and rural areas.

Table 4. Fair financial contribution index (FFCI) in Iran, 2012

\begin{tabular}{llll}
\hline FFCI & INSURED & UNISURED & TOTAL \\
\hline URBAN & 0.851351 & 0.835981 & 0.8463 \\
RURAL & 0.822062 & 0.802261 & 0.8193 \\
TOTAL & 0.83914 & 0.830456 & 0.837 \\
\hline
\end{tabular}


The proportion of people who encountered catastrophic health related costs at the national level is $2.9 \%$ (Table 5). Catastrophic medical costs are imposed on about $3 \%$ of uninsured and $2.8 \%$ of insured households. This index varies from the lowest at $2.2 \%$ in insured urban households and the highest at $5.3 \%$ in uninsured rural households. Being insured has not had much impact on percentage of population exposed to catastrophic medical costs (about $-0.2 \%$ unit), and incidence of such costs is about $70 \%$ higher in rural compared to urban areas. The insured to uninsured population encountered catastrophic health ratio in urban and rural areas is $82 \%$ and $74 \%$, respectively. Hence, it is clear that insurance cover in rural areas has affected greater reduction in catastrophic medical costs compared to urban areas.

Table 5. Percentage of households with catastrophic payments (\%CAT) in Iran in 2012

\begin{tabular}{llll}
\hline CHE & INSURED & UNISURED & TOTAL \\
\hline URBAN & 0.022271 & 0.027057 & 0.0238 \\
RURAL & 0.039517 & 0.053373 & 0.0413 \\
TOTAL & 0.028063 & 0.030007 & 0.0285 \\
\hline
\end{tabular}

\section{Discussion}

Higher RE than zero in rural and urban areas indicates better income distribution after medical payments due tohousehold's financial contributions. Studies by Hajizadeh, Luke B, Connely (2010) and Ghiasvand et al. (2015) also suggest progressivity of funding medical costs in Iran, resulting in improved income distribution in favor of the poor.

Unlike in rural areas, RE index is higher than both urban insured (compared to uninsured) and rural mean, which has led to greater mean medical costs redistribution in urban areas compared to rural, and also significantly higher RE index among the insured compared to uninsured due to possible differences in insurance cover in urban areas, where adverse selection is likely to occur in the absence of a universal medical insurance coverage. This means that people in urban areas with heavier medical costs have greater tendency to use insurance cover. The difference in insurance coverage among various income deciles, and the difference in insured and uninsured levels in urban areas can be regarded as signs of this situation. Despite benefiting from medical insurance, income redistribution among insured urban areas makes people more vulnerable to heavy medical costs. In rural areas, more equitable access to medical services and universal medical insurance coverage have been able to adjust the effect of medical costs on income distribution, which has led to lower RE index among the rural insured people compared to the uninsured.

Higher RE index in urban areas compared to rural, and also among insured compared to uninsured groups have notable consequences on impoverishment index of medical expenditure among these groups, such that this index is lower in urban areas and insured people. This agrees with the results obtained by Razavi et al. (2005) and Alizadeh H. M. \& Fazaeli A. (2005). According to national average, although insured households have incurred greater costs, they are $37 \%$ less likely to suffer poverty compared to uninsured households. However, poverty headcount difference due to medical costs $(\mathrm{DH})$ is not much different among insured and uninsured households, but significantly higher in the rural insured compared to urban uninsured. This may be mainly due to lower affordability of rural households and better access to fuller insurance in urban areas.

According to FFCI, medical costs are significantly better distributed among urban households compared to rural ones. Although insurance cover has been able to improve FFCI, it has failed to improve distribution of medical costs in rural areas even to the same level as uninsured urban households. Other studies have also shown higher level of FFCI in urban areas and the significant effect of insurance on this index (Fazaeli et al., 2015; Razavi, Hassanzadeh, \& Basmenji, 2005; Alizadeh \& Fazaeli, 2005).

In addition to distribution of costs, in burden approach, population exposed to catastrophic health expenditure, as a threshold index, is also especially important.

In both rural and urban areas, this index is lower among the insured compared to the uninsured, which concurs with studies across Iran (Mehrara \& Fazaeli, 2010) and provinces (Kavosi et al., 2014; Kavosi et al., 2012). Studies by Somkotra \& Lagrada (2008) in Thailand, and Sun et al. (2009) in rural areas also show that insurance cover reduces catastrophic costs, especially among poorer households.

Despite the positive effect of insurance cover in reducing incidence of catastrophic costs, insurance has failed to 
improve this index among the insured in rural areas to mean level in urban areas, and it is still significantly lower. Greater capacity to pay (CTP) in urban areas appear to be a major factor in better distribution of costs, and despite improvements due to insurance, there is still a wide gap between rural and urban areas.

The present study showed that medical services are used by the insured 1.4 times more than the uninsured households, even in relation to admission services (1.3 times), which suggest high levels of risks or risk of diseases that ensure use of such services among insured people, or low use of admission services by uninsured people. In the first assumption, insurance organizations can be expected to have been exposed to inverse selection, resulting in accumulation of high-risk people and their risk of financial instability. In the other assumption, several factors including lack of access to services or unaffordable admission costs can lead to low rate of admission of uninsured people.

\section{Conclusion}

A more ubiquitous insurance coverage in rural areas has failed to close the gap with urban areas in terms of distribution of medical costs. Given that indices of benefiting from medical services (especially in inpatient services) in urban areas are close to those in rural areas, low affordability of rural households and inadequate comprehensiveness of insurance coverage on the one hand, and absence of a universal insurance cover, especially in urban areas, on the other hand, can be considered among important factors in this regard.

\section{Acknowledgments}

This study was part of a PhD thesis supported by Iran University of Medical Sciences (Grant No: IUMS/SHMIS /2015/360).

The first and corresponding authors had the key roles in designing the study and statistical analysis; the others contributed to data collection and writing the preliminary draft of the manuscript.

This study was approved by the Ethics Committee of Iran University of Medical Sciences (Approved ethical code: $93 / \mathrm{d} / 105 / 4849)$.

This study has been funded and supported by School of Health Management and Information Sciences, Iran University of Medical Sciences (IUMS).

\section{Conflict of Interest}

The authors declare that there is no conflict of interests regarding the publication of this paper.

\section{References}

Alizadeh, H. M., \& Fazaeli, A. (2005). Measuring equity in health financing index of Iran. Social Welfare Quarterly, 5(1), 253-78.

Economic, F. (2004). Social and Cultural Development Plan of the Islamic Republic of Iran, 2005-2009 Management and Planning Organization Law. Tehran.

Fazaeli, A. A., Seyedin, H., Moghaddam, A. V., Delavari, A., Salimzadeh, H., Varmazyar, H., \& Fazaeli, A. A. (2015). Fairness of Financial Contribution in Iranian Health System: Trend Analysis of National Household Income and Expenditure, 2003-2010. Global Journal of Health Science, 7(5), 260. http://dx.doi.org/10. 5539/gjhs.v7n5p260

Ghiasvand, H., Naghdi, S., Abolhassani, N., Shaarbafchizadeh, N., \& Moghri, J. (2015). Iranian Households' Payments on Food and Health Out-of-Pocket Expenditures: Evidence of Inequality. Iranian Journal of Public Health, 44(8), 1103.

Hajizadeh, M., \& Connelly, L. B. (2010). Equity of health care financing in Iran: The effect of extending health insurance to the uninsured. Oxford Development Studies, 38(4), 461-476. http://dx.doi.org/10.1080/136 00818.2010.524697

Kavosi, Z., Keshtkaran, A., Hayati, R., Ravangard, R., \& Khammarnia, M. (2014). Household financial contribution to the health System in Shiraz, Iran in 2012. International journal of health policy and management, 3(5), 243. http://dx.doi.org/10.15171/ijhpm.2014.87

Kavosi, Z., Rashidian, A., Pourreza, A., Majdzadeh, R., Pourmalek, F., Hosseinpour, A. R., ... Arab, M. (2012). Inequality in household catastrophic health care expenditure in a low-income society of Iran. Health Policy and Planning, 27(7), 613-623. http://dx.doi.org/10.1093/heapol/czs001

Kutzin, J. (2013). Health financing for universal coverage and health system performance: Concepts and implications for policy. Bulletin of the World Health Organization, 91(8), 602-611. http://dx.doi.org/10. 


\section{1/BLT.12.113985}

Larijani, B., Delavari, A., Damari, B., Moghadam, A. V., \& Majdzadeh, R. (2009). Health policy making system in Islamic Republic of Iran: Review an experience. Iranian Journal of Public Health, 38(Suppl. 1), 1-3.

McIntyre, D. (2010). WHR 2000 to WHR 2010: What progress in health care financing? Health policy and planning, 25(5), 349-351. http://dx.doi.org/10.1093/heapol/czq033

Mehrara, M. O. H. S. E. N., \& Fazaeli, A. A. (2010). Health finance equity in Iran: An analysis of household survey data (1382-1386). Journal of Health Administration, 13(40), 51-62.

Moghaddam, A. V., Damari, B., Alikhani, S., Salarianzedeh, M. H., Rostamigooran, N., Delavari, A., \& Larijani, B. (2013). Health in the 5th 5-years Development Plan of Iran: Main challenges, general policies and strategies. Iranian Journal of Public Health, 42(Supple1), 42.

Murray, C. J., \& Evans, D. (2006). Health systems performance assessment. Office of Health Economics.

Murray, C. J., \& Frenk, J. (2000). A framework for assessing the performance of health systems. Bulletin of the world Health Organization, 78(6), 717-731.

Murray, C. J., Xu, K., Klavus, J., Kawabata, K., Hanvoravongchai, P., Zeramdini, R., ... Evans, D. B. (2003). Assessing the distribution of household financial contributions to the health system: Concepts and empirical application. Health systems performance assessment: Debates, methods and empiricism (p. 12). Geneva: World Health Organization.

O'Donnell, O. A., \& Wagstaff, A. (2008). Analyzing health equity using household survey data: A guide to techniques and their implementation. World Bank Publications.

Razavi, S. M., Hassanzadeh, A., \& Basmenji, K. (2005). Fairness in financial contribution in the health system. Tehran: Andishmand publication. [In Persian].

Reynolds, M., \& Smolensky, E. (2013). Public expenditures, taxes, and the distribution of income: The United States, 1950, 1961, 1970. Academic Press.

Somkotra, T., \& Lagrada, L. P. (2008). Payments for health care and its effect on catastrophe and impoverishment: Experience from the transition to Universal Coverage in Thailand. Social Science \& Medicine, 67(12), 2027-2035. http://dx.doi.org/10.1016/j.socscimed.2008.09.047

Sun, X., Jackson, S., Carmichael, G., \& Sleigh, A. C. (2009). Catastrophic medical payment and financial protection in rural China: Evidence from the New Cooperative Medical Scheme in Shandong Province. Health Economics, 18(1), 103-119. http://dx.doi.org/10.1002/hec.1346

Van Kerm, P. (2009). Sgini-Generalized Gini and concentration coefficients (with factor decomposition) in Stata. CEPS/INSTEAD, Luxembourg.

World Health Organization. (2000). The world health report 2000: Health systems: Improving performance. World Health Organization.

Xu, K. (2005). Distribution of health payments and catastrophic expenditures Methodology.

Zare, H., Trujillo, A. J., Driessen, J., Ghasemi, M., \& Gallego, G. (2014). Health inequalities and development plans in Iran; an analysis of the past three decades (1984-2010). International Journal for Equity in Health, 13(1), 42. http://dx.doi.org/10.1186/1475-9276-13-42

\section{Copyrights}

Copyright for this article is retained by the author(s), with first publication rights granted to the journal.

This is an open-access article distributed under the terms and conditions of the Creative Commons Attribution license (http://creativecommons.org/licenses/by/3.0/). 